\title{
Effect of suspension system in the lateral stability of railway freight trucks
}

\author{
H Molatefi $^{1 *}$, M Hecht ${ }^{2}$, and M H Kadivar ${ }^{3}$ \\ ${ }^{1}$ Railway Engineering School, Iran University of Science and Technology, Narmak, Tehran, Iran \\ ${ }^{2}$ Department of Rail Vehicles, TU Berlin, Germany \\ ${ }^{3}$ Department of Mechanical Engineering, Shiraz University, Shiraz, Iran
}

The manuscript was received on 24 October 2006 and was accepted after revision for publication on 8 June 2007.

DOI: 10.1243/09544097JRRT121

\begin{abstract}
In the current research an empty freight wagon with BA652 and an old BA661 bogies have been modelled. Non-linear creep forces with spin moment between wheel and rail have been used and also all impacts and friction forces have been modelled. The characteristics of primary suspension systems for BA652 and an old BA661 have been evaluated by means of test. Non-linear equations of motions and kinematical constraints have been solved in time domain and limit cycles have been showed. Both primary and secondary hunting can be seen in responses of wagon. For BA652 there are non-linear and linear critical speeds and also saddle nodes but for old BA661 the situation is too critical and the system can oscillate in very low speeds.
\end{abstract}

Keywords: freight wagon, BA661, BA652, non-linear, hunting, limit cycle

\section{INTRODUCTION}

Dynamics of rail vehicles are non-linear [1] and have been considered for several decades. In freight trucks dry friction, impacts and also the contact between wheel and rail generate non-linear kinematical and dynamical terms [2-7]. Usual freight bogies have two wheelsets, which are parallel and are connected to the bogie frame. The wagon weight is transferred to the track through vehicle's suspension system that has essential role in the behaviour of wagon. Hunting stability is primarily a function of the bending and shear stiffness between two wheelsets. Bogies with low bending stiffness generally are known as 'steering bogies' [8]. These bogies use the longitudinal creep forces to deflect the longitudinal springs, which create the bending stiffness. This permits the wheelsets to align with an almost radial position on the curves. BA type bogies are known as steering axle bogies and Y25 type bogies are known as rigid axle bogies [9]. Critical speed and limit cycles in the dynamics of an empty Y25-freight truck have been analysed in reference [10]

*Corresponding author: Railway Engineering School, Iran University of Science and Technology, PO Box 14515/1179, Narmek, Tehran, Iran.email: molatefi@iust.ac.ir or molatefi@gmail.com by authors. In the current paper lateral stability of an empty freight wagon with BA652 and an old BA661 bogies have been analysed.

Leaf or parabolic springs have been used from 1890 and have been adapted in bogie suspension systems since 1925. Dry friction between leaves generates damping in these springs. BA652 and BA661 have been designed for axle load of 22.5 ton (Fig. 1). Chain links (or swing hangers) connect the bogie to the leaf spring of the suspension system that rests on the axle box (Fig. 2). This arrangement allows the axle box to move in both longitudinal and lateral directions. As Fig. 2 shows in addition to friction between leaves of parabolic springs there are frictions between bolt and parabolic spring, bolt and chain stone and also chain link and chain stone. Motions are limited only by the play of the axle box in the axle horns that is $\pm 6 \mathrm{~mm}$ in longitudinal and $\pm 23 \mathrm{~mm}$ in lateral directions. Main differences of primary suspension systems of BA661 and BA652 are in their leaf springs and length of chain links (Fig. 2).

Empty wagons are one of the sources for noise in the freight transportation. They have low critical speed and can oscillate with high amplitudes. In this research completely non-linear equations of motions and constraints for BA661 and BA652 freight trucks with empty wagon and $25^{\circ}$ of freedom have been derived. 


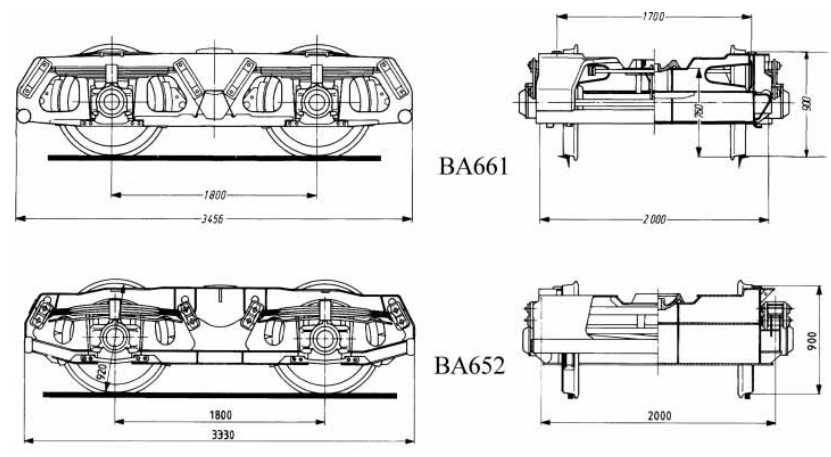

Fig. 1 BA652 and BA661 freight bogies

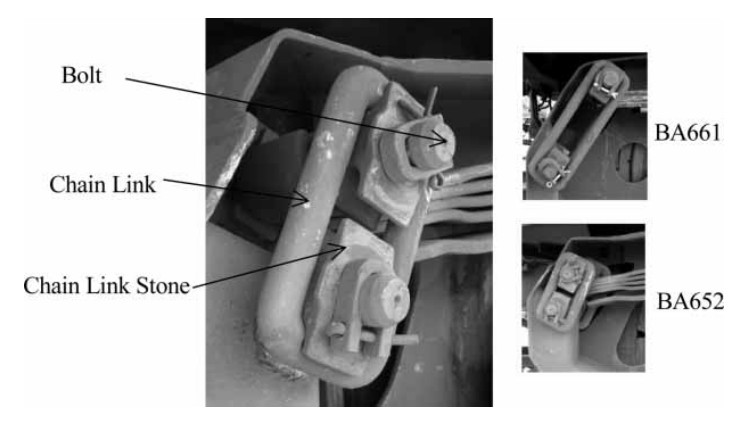

Fig. 2 Chain links in BA661 and BA652

The property of primary suspensions had been tested in TU-Berlin, all dry frictions have been modelled by Kolsch-method and impacts in clearances have been modelled by non-linear springs. Table 1 shows values of masses, position for centre of masses, and moment of inertias for empty wagon of Eaos807.

Wheel/rail contact creep coefficients and kinematical constraints have been derived by means of RSGEO software. Wheelset and rail have been defined in Table 2.

\section{SIMULATION OF FORCES}

\subsection{Forces in primary suspension}

Impacts between parts after clearances have been modelled by non-linear springs with high stiffness of
Table 2 Wheel and rail definitions

\begin{tabular}{|c|c|c|c|}
\hline $\begin{array}{l}\text { Wheel } \\
\text { profile }\end{array}$ & $\begin{array}{l}\text { Wheel } \\
\text { base }\end{array}$ & $\begin{array}{l}\text { Wheelset tape } \\
\text { circle distance }\end{array}$ & $\begin{array}{l}\text { Wheel } \\
\text { radius }\end{array}$ \\
\hline S1002 & $1800 \mathrm{~mm}$ & $1500 \mathrm{~mm}$ & $460 \mathrm{~mm}$ \\
\hline Rail profile & Rail gauge & Inclination & Type \\
\hline UIC60 & $1435 \mathrm{~mm}$ & $1 / 40$ & $\begin{array}{l}\text { Straight/no } \\
\text { irregularities }\end{array}$ \\
\hline
\end{tabular}

$10^{7} \mathrm{~N} / \mathrm{m}$ (Fig. 3). The stiffness must be high enough to simulate solid contact.

A measurement structure (Fig. 4) for primary suspension systems with parabolic springs has been developed in TU-Berlin [11]. Results show that there are hysteresis loops in three directions. Hysteresis can be assumed as in Fig. 5 for different vertical preloads. Table 3 shows the results for vertical load of $18.9 \mathrm{kN}$.

To model primary suspension force elements, Kolsch-method [12] has been used that explained in reference [10].

\subsection{Forces between carbody and bogies}

Bogie frame is connected to the carbody through central pivot. Figure 6 shows the central pivot as a

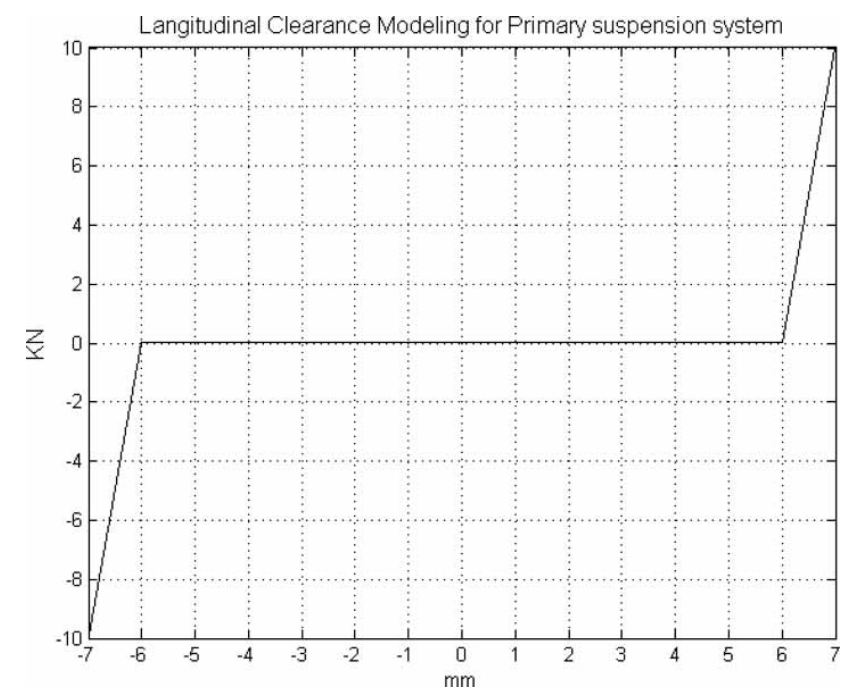

Fig. 3 Non-linear spring for axle box clearance in longitudinal direction

Table 1 Mass, moment of inertia, and centre of mass for the freight truck

\begin{tabular}{|c|c|c|c|c|c|c|}
\hline & \multirow{2}{*}{$\begin{array}{l}\text { Center of } \\
\operatorname{mass}^{\mathrm{a}}(\mathrm{m})\end{array}$} & \multicolumn{3}{|c|}{ Moment of inertia $\left(\mathrm{kg} \mathrm{m}^{2}\right)$} & \multicolumn{2}{|c|}{ Mass (kg) } \\
\hline & & $I_{x x}$ & $I_{y y}$ & $I_{z z}$ & One unit & \\
\hline $\begin{array}{l}\text { Wheelset with } \\
\text { axle box }\end{array}$ & $h_{\mathrm{wh}}=0.46$ & 825 & 121 & 837 & 1300 & \\
\hline Bogie & $h_{\mathrm{b}}=0.66$ & 1372 & 1589 & 2875 & 2150 & Bogie: 4750 \\
\hline Carbody & $h_{\mathrm{c}}=1.31$ & 11389 & 219667 & 225378 & 11400 & \\
\hline Empty wagon & 0.9648 & & & & & \\
\hline
\end{tabular}

${ }^{\mathrm{a}}$ Centre of mass is with respect to the railhead surface 


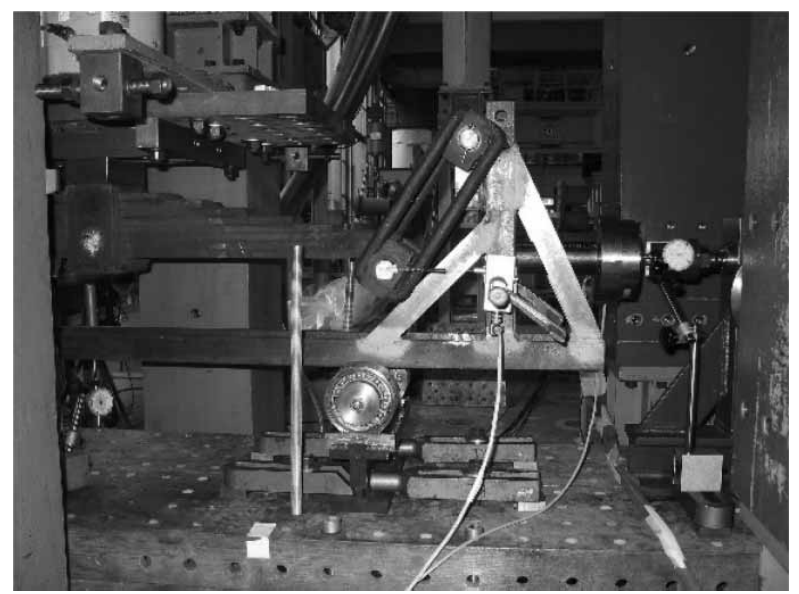

Fig. 4 Test structure for primary suspensions with leaf springs

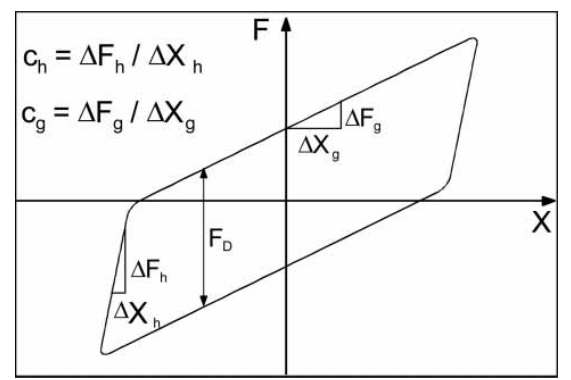

Fig. 5 Hysteresis in the force-displacement diagram

spherical joint. The bogie frame has angular motions with respect to carbody about the joint centre. Contact surfaces and their relative motions generate dry friction in the central pivot. Researches and tests show that the moment forces in the central pivot have maximum value [11] that can be evaluated as equation (1). These values are in the slip mode and in the stick mode the angular stiffness is about $10^{7} \mathrm{Nm} / \mathrm{rad}(0.22[\mathbf{1 1}]$ has been used for dry friction coefficient).

$$
\begin{aligned}
& M_{x}=M_{y}=0.17 \cdot \mu_{\text {CentPiv }} \cdot F_{N} \\
& M_{z}=0.18 \cdot \mu_{\text {CentPiv }} \cdot F_{N}
\end{aligned}
$$

Figure 7 shows side bearers; $3 \mathrm{~mm}$ clearance has been considered in simulations, which is approximately equal to $0.0035 \mathrm{rad}$ relative roll-movement of

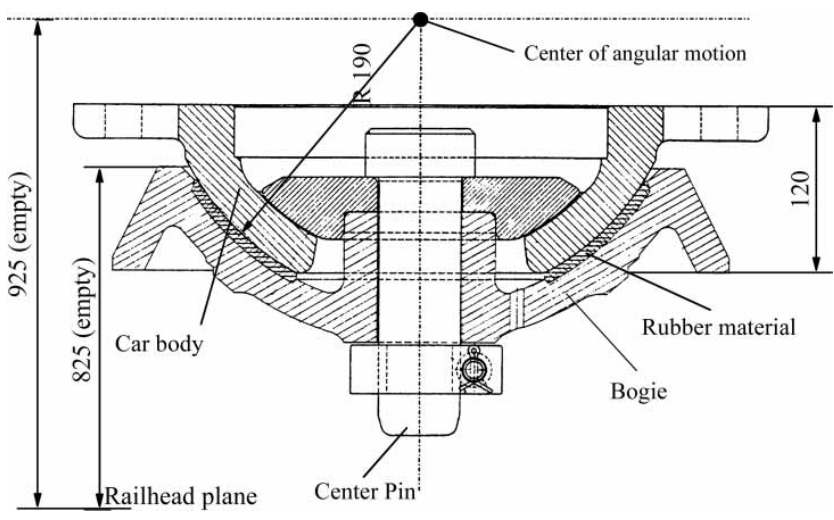

Fig. 6 Central pivot (all dimensions in $\mathrm{mm}$ )

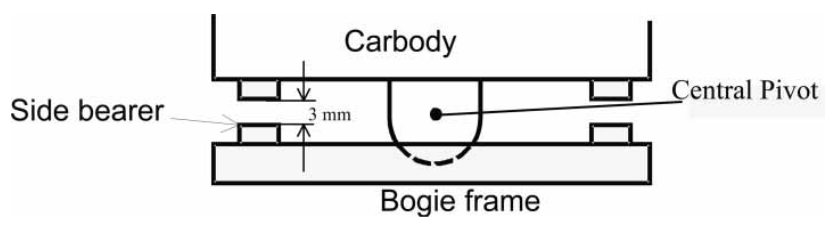

Fig. 7 Side bearer

carbody and bogie. Dry frictions between side bearers and carbody have been modelled using Kolschmethod with 0.22 for dry friction coefficient and $10^{6} \mathrm{~N} / \mathrm{m}$ for stick stiffness.

\subsection{Wheel/rail contact forces}

Non-linear creep forces model including the effect of spin moment $[13,14]$ have been used to model wheel/rail contact forces. This model has been explained in reference [10].

\section{EQUATIONS OF MOTIONS}

As common, rotations around longitudinal, lateral and vertical axis have been defined as roll $(\phi)$, pitch $(\chi)$, and yaw $(\psi)$. Wheelsets have four degrees of freedom (longitudinal, lateral, pitch, and yaw motions). Vertical and roll motions of wheelsets are dependent to lateral and yaw motions of wheelsets and can be calculated from kinematical constraints between wheelset and track. Bogies have four degrees of freedom (lateral, vertical, roll, and yaw motions). Track is straight without irregularity and the pitch motion of bogie frame can

\begin{tabular}{|c|c|c|c|c|c|c|c|c|c|}
\hline & \multicolumn{3}{|c|}{$X$} & \multicolumn{3}{|c|}{$Y$} & \multicolumn{3}{|c|}{$Z$} \\
\hline & $C_{\mathrm{h}}(\mathrm{N} / \mathrm{m})$ & $C_{\mathrm{g}}(\mathrm{N} / \mathrm{m})$ & $F_{\mathrm{D}}(\mathrm{kN})$ & $C_{\mathrm{h}}(\mathrm{N} / \mathrm{m})$ & $C_{\mathrm{g}}(\mathrm{N} / \mathrm{m})$ & $F_{\mathrm{D}}(\mathrm{kN})$ & $C_{\mathrm{h}}(\mathrm{N} / \mathrm{m})$ & $C_{\mathrm{g}}(\mathrm{N} / \mathrm{m})$ & $F_{\mathrm{D}}(\mathrm{kN})$ \\
\hline BA661 & $6.7 \times 10^{5}$ & $2.2 \times 10^{5}$ & 1.6 & $1.5 \times 10^{5}$ & $1.0 \times 10^{5}$ & 0.6 & $7.2 \times 10^{6}$ & $2.3 \times 10^{6}$ & 13.0 \\
\hline BA652 & $9.7 \times 10^{6}$ & $4.3 \times 10^{5}$ & 3.2 & $8.6 \times 10^{5}$ & $2.1 \times 10^{5}$ & 1.2 & $4.3 \times 10^{6}$ & $9.0 \times 10^{5}$ & 7.0 \\
\hline
\end{tabular}

Table 3 Test results for BA652 and BA661 suspensions in empty wagon (Fig. 5) 
be neglected. Carbody (with bogies) is massive and so in the longitudinal direction acceleration is ignorable and so longitudinal velocity is considered to be constant or known for bogies and car body. Assuming the spherical joint in central pivots of carbody reduces the freedom of carbody. Carbody has one degree of freedom (roll motion) around connecting line of its central pivots.

In the current research stiffness and damping of primary suspension have been evaluated by means of test and so equations of motions for this freight truck is the same as in reference [10]. Differences are in bogie weight characteristics, side bearers, clearances, and property of primary suspension. As Fig. 7 shows, side bearer of this type of bogies does not have spring, and relative roll motion of carbody and bogie differs with Y25 bogies. Also for relative yaw motion of carbody and bogies, there is no contact surface with dry friction in the side bearer especially for the straight track.

In results, numbers $1,2,3$, and 4 , have been used for first, second, third, and fourth wheelsets, 5 and 6 have been used for first and second bogie frame and 7 has been used for carbody.
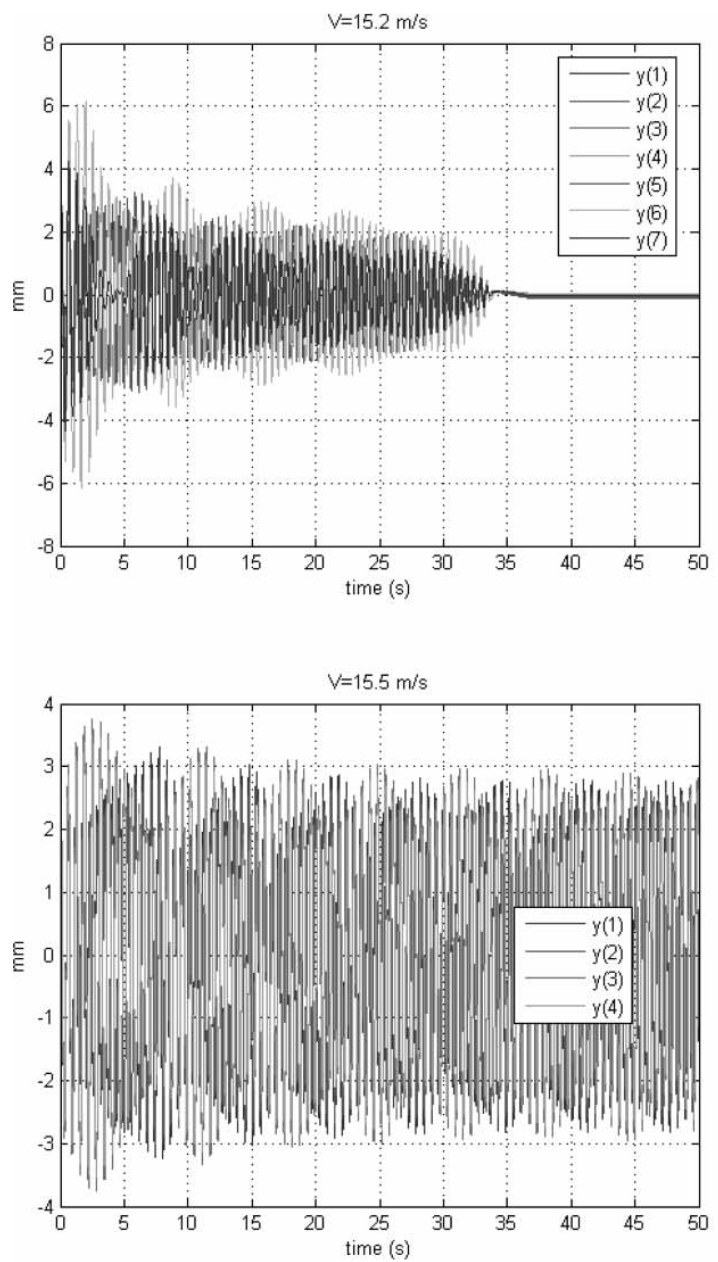

\section{RESULTS}

Normally critical speed means non-linear critical speed in the railway vehicle system dynamics. The non-linear critical speed is the lowest speed for which a periodical motion exists and it will be determined by the bifurcation analysis. Periodical motions appear with two saddle node bifurcations. The velocity of the first saddle node bifurcation is the non-linear critical velocity. This velocity can be found by driving with perturbed vehicle at a velocity enough more than critical speed. After some time the solution will be converged to a limit cycle oscillation. The next step is an adiabatic reduction of the velocity that can be done by making the velocity a linear function of time. This reduction is done until passing the saddle node, which is clearly seen as the amplitude of the oscillation suddenly drops to zero.

The dynamical systems of freight trucks are very complicated due to the characteristics of the nonsmoothness and the discontinuities caused by impacts and stick - slip motions originating from clearance and dry friction. The time for computation of the necessary
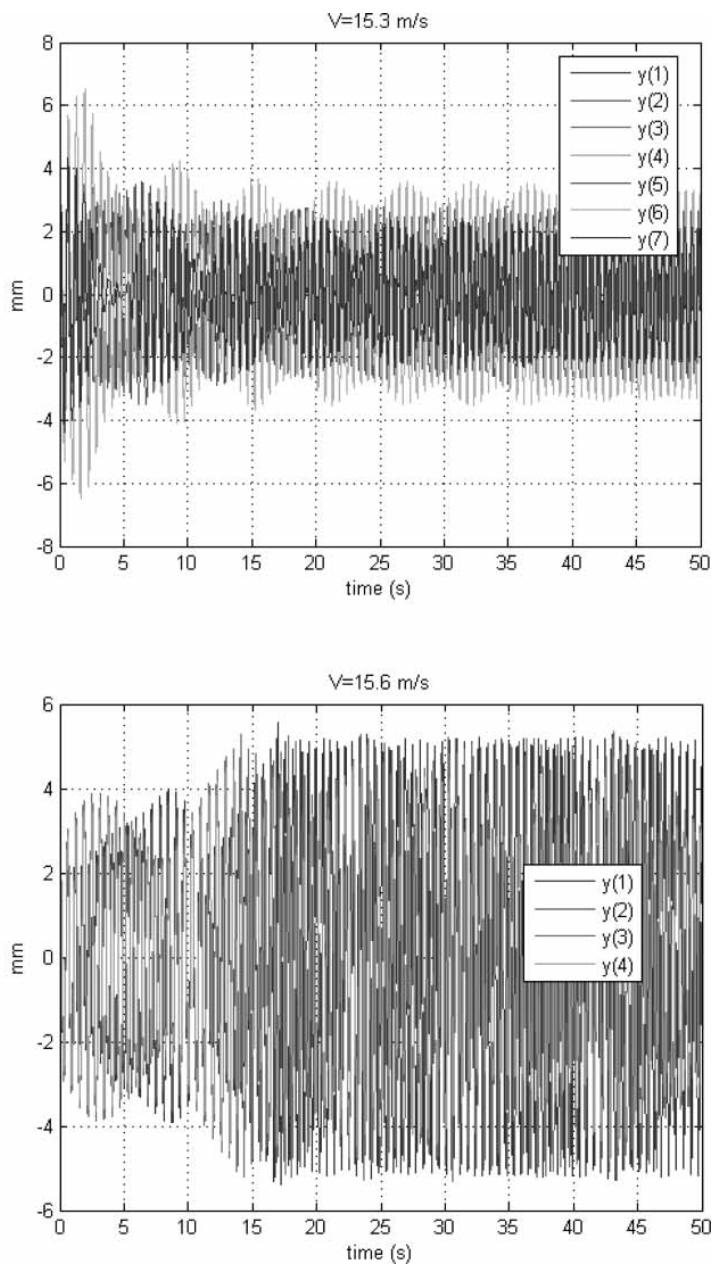

Fig. 8 Search for limit cycles in different speeds 
data for fine visualization of bifurcation is very long. To find limit cycles for non-linear systems there is not a unique method. In the current research perturbed wagon has been simulated with different speeds (starting from $1.0 \mathrm{~m} / \mathrm{s}$ and with step size of $1.0 \mathrm{~m} / \mathrm{s}$ ). With this method limit cycles can be seen and saddle nodes can be found as a jump in the limit cycle amplitude. To find the other saddle node, vehicle has been simulated at speed more than the speed with jumped amplitudes. After $10 \mathrm{~s}$, the speed has been decreased linearly until the amplitudes of oscillations have become zero.
In addition, the speed has been increased to find the behaviour in the speeds more than critical speed.

\subsection{Critical speed and limit cycles for BA652}

Figure 8 shows the amplitude for lateral oscillations in different speeds and as can be seen the limit cycle appears in $15.3 \mathrm{~m} / \mathrm{s}$. There is a jump in the amplitude at speed $15.6 \mathrm{~m} / \mathrm{s}$. Amplitudes of lateral oscillations for wheelsets in speeds between 15.6 and $19 \mathrm{~m} / \mathrm{s}$ are about $5 \mathrm{~mm}$. For $20 \mathrm{~m} / \mathrm{s}$ these amplitudes are less than $3 \mathrm{~mm}$.
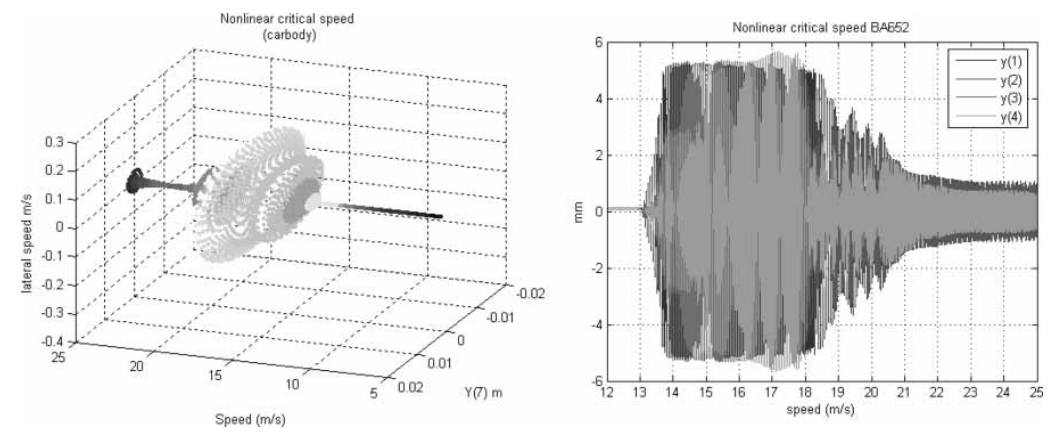

Fig. 9 Non-linear critical speed for the wagon with BA652 bogie
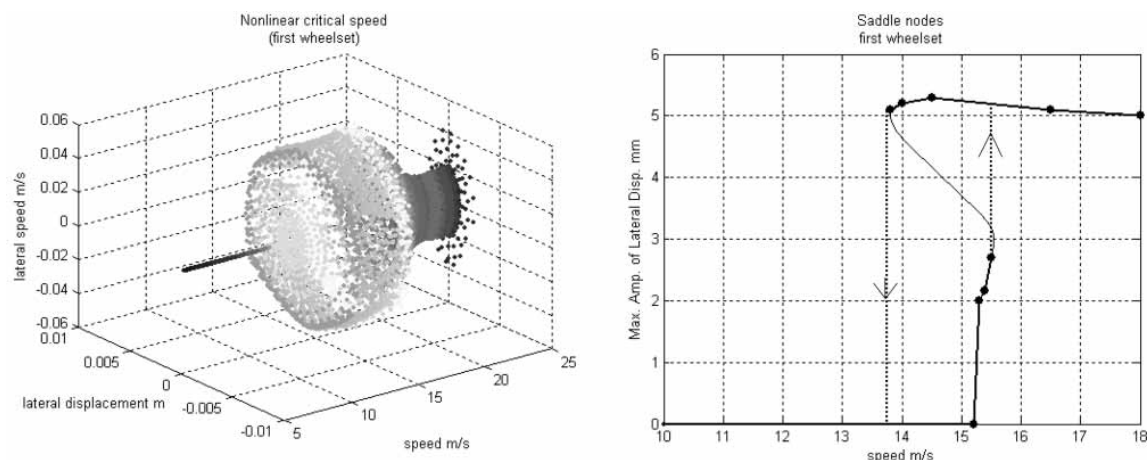

Fig. 10 Non-linear critical speed and saddle nodes (BA652)
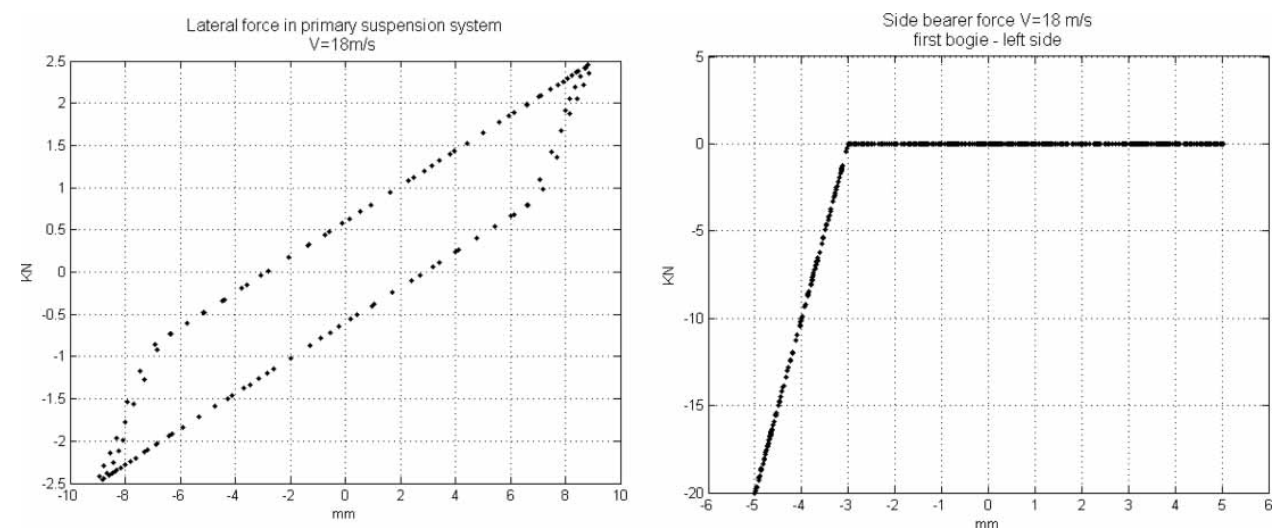

Fig. 11 Lateral force in the primary suspension system and normal force in side bearer (BA652) 
To find the critical speed, simulation has been started from speed $25 \mathrm{~m} / \mathrm{s}$ and after $10 \mathrm{~s}$ the speed has been reduced, to $0.02 \mathrm{~m} / \mathrm{s}$. Non-linear critical speed for this wagon is $13.8 \mathrm{~m} / \mathrm{s}(50 \mathrm{~km} / \mathrm{h})$. As Fig. 9 shows all lateral displacements jump down by $13.8 \mathrm{~m} / \mathrm{s}$. The left side of Fig. 9 shows the change in the limit cycle diagram of carbody with speed.

In Fig. 10 positions of two saddle-nodes can be seen. The first one or the critical speed is about $13.8 \mathrm{~m} / \mathrm{s}$ and the second one is about $15.6 \mathrm{~m} / \mathrm{s}$. The speed $15.2 \mathrm{~m} / \mathrm{s}$ is known as linear critical speed and it is more than non-linear critical speed.
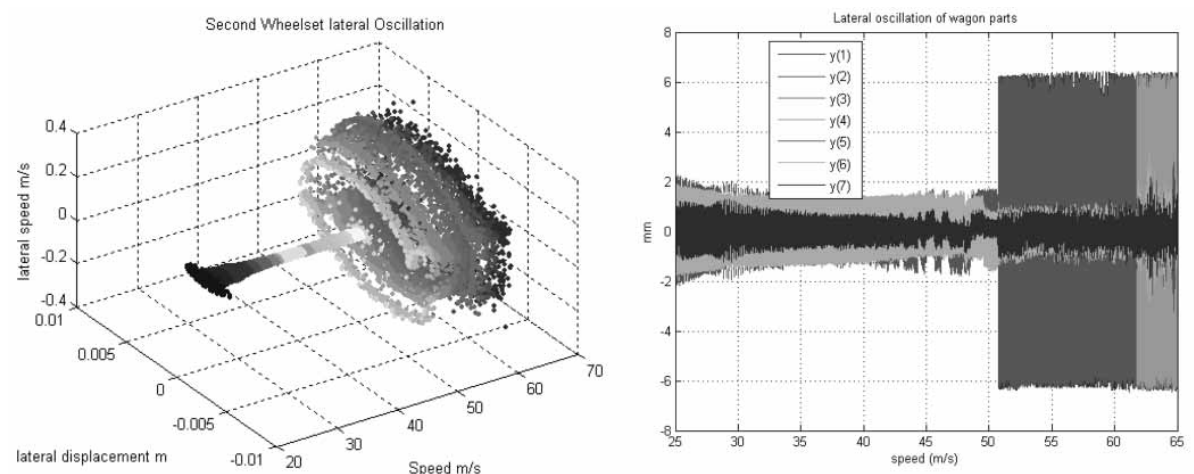

Fig. 12 Changes of lateral displacements and limit cycles by speed (BA652)
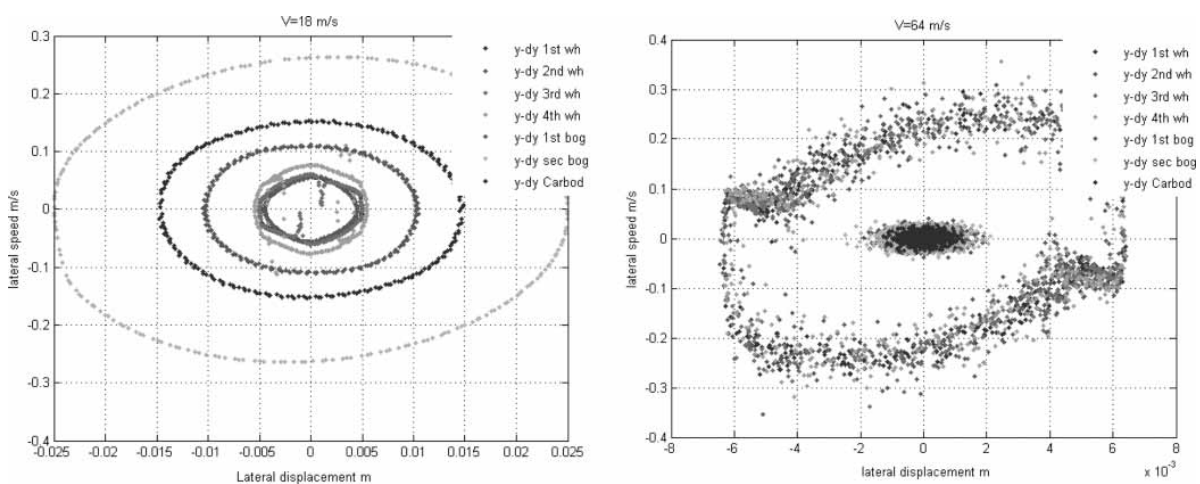

Fig. 13 State-space diagrams for primary and secondary hunting (BA652)
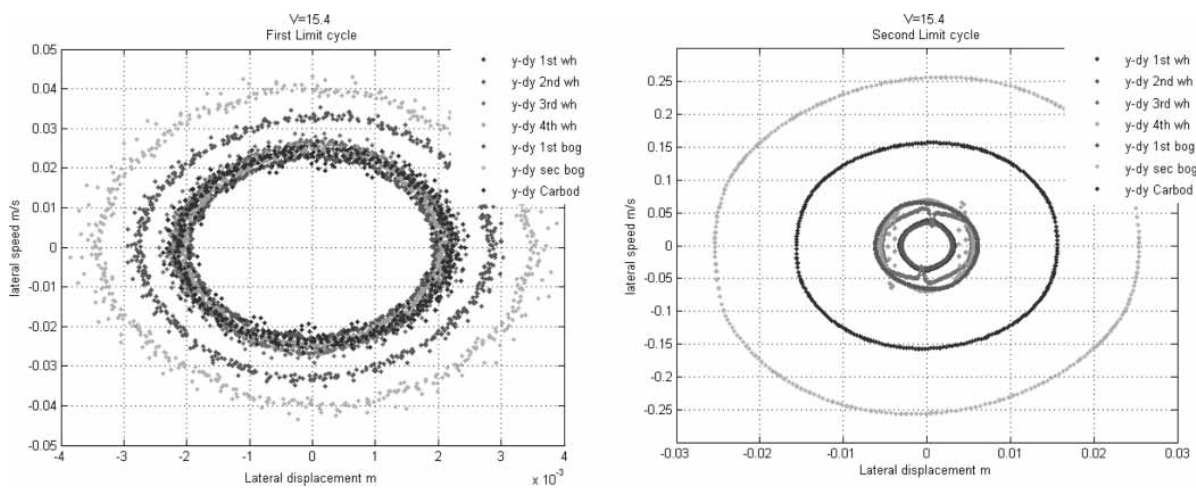

Fig. 14 Two different limit cycles for speed $15.4 \mathrm{~m} / \mathrm{s}$ (BA652) 
bogie frames are more than two times of wheelsets and so wagon is in primary hunting mode. In the $64 \mathrm{~m} / \mathrm{s}$, wheelsets have $6 \mathrm{~mm}$ lateral oscillations and so they have flange contact. Wagon in the $64 \mathrm{~m} / \mathrm{s}$ has secondary hunting mode and oscillations of bogies are less than the wheelsets.

In Fig. 14 two limit cycles for $15.4 \mathrm{~m} / \mathrm{s}$ have been showed. For the second limit cycle, simulation has been started from speed $17 \mathrm{~m} / \mathrm{s}$ and after $10 \mathrm{~s}$ the speed has been reduced to $0.1 \mathrm{~m} / \mathrm{s}$ to reach $15.4 \mathrm{~m} / \mathrm{s}$ and in this speed wagon has been simulated for $100 \mathrm{~s}$. As figure shows there are completely different
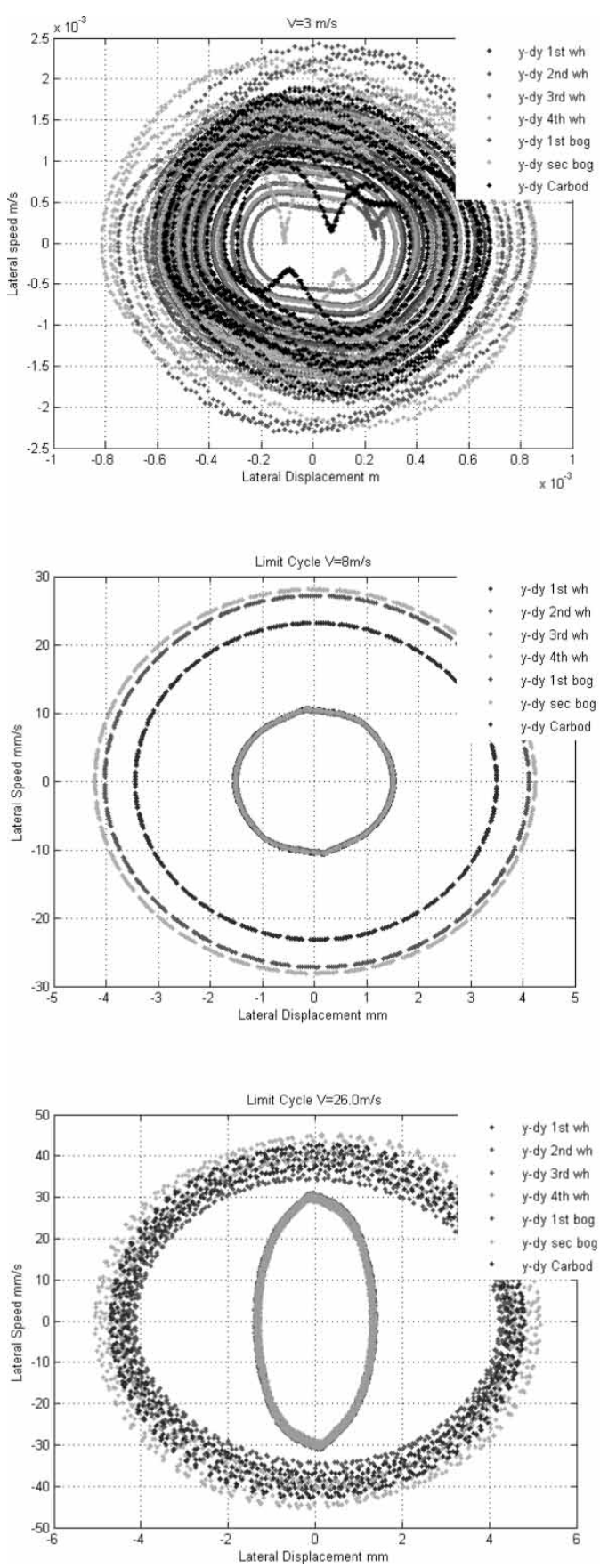

conditions between these limit cycles. Concentrating in the second limit cycle (oscillation of first wheelset) and comparing with Fig. 10, shows that the responses of wagon depend on initial conditions.

\subsection{Critical speed and limit cycles for BA661}

Results for BA661 show that there are limit cycles in low speeds and the condition is very critical. For $3 \mathrm{~m} / \mathrm{s}$ the oscillation of perturbed wagon decreases after $100 \mathrm{~s}$. Figure 15 shows that limit cycle appears in
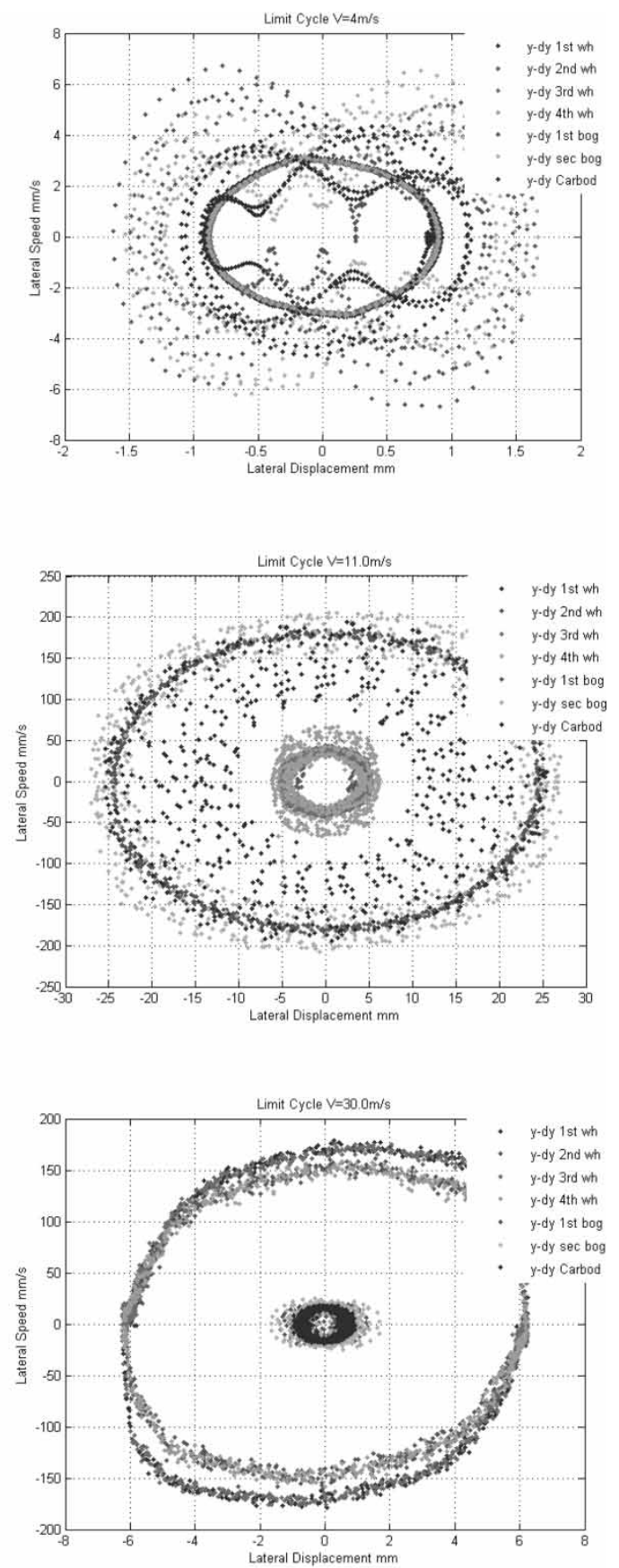

Fig. 15 State-space diagrams for limit cycles in different speed (BA661) 

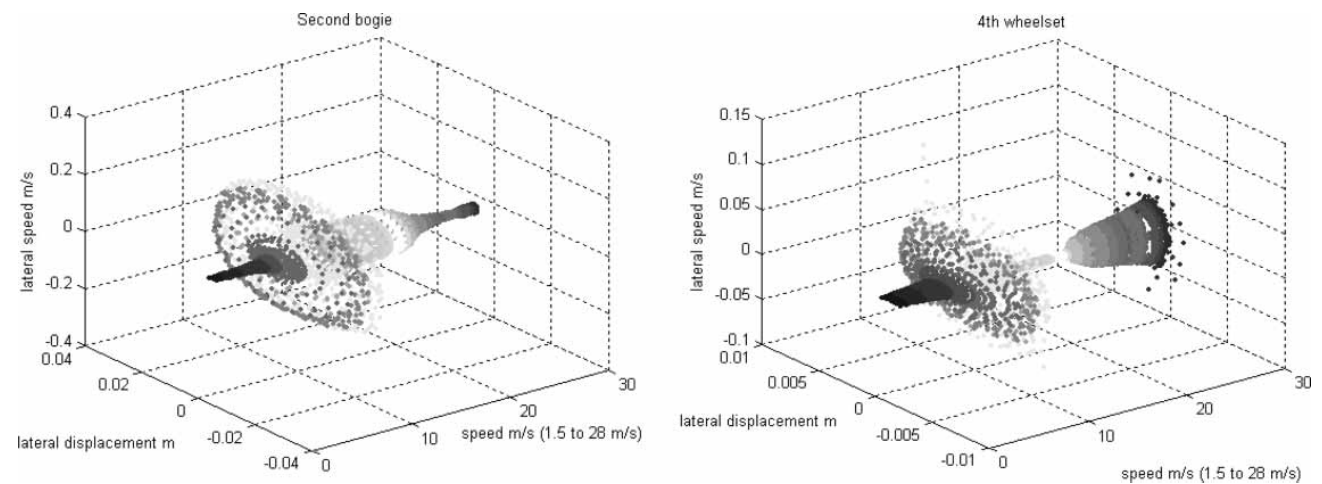

Fig. 16 Non-linear critical speed for BA661 (speed from 28 to $1.5 \mathrm{~m} / \mathrm{s}$ )
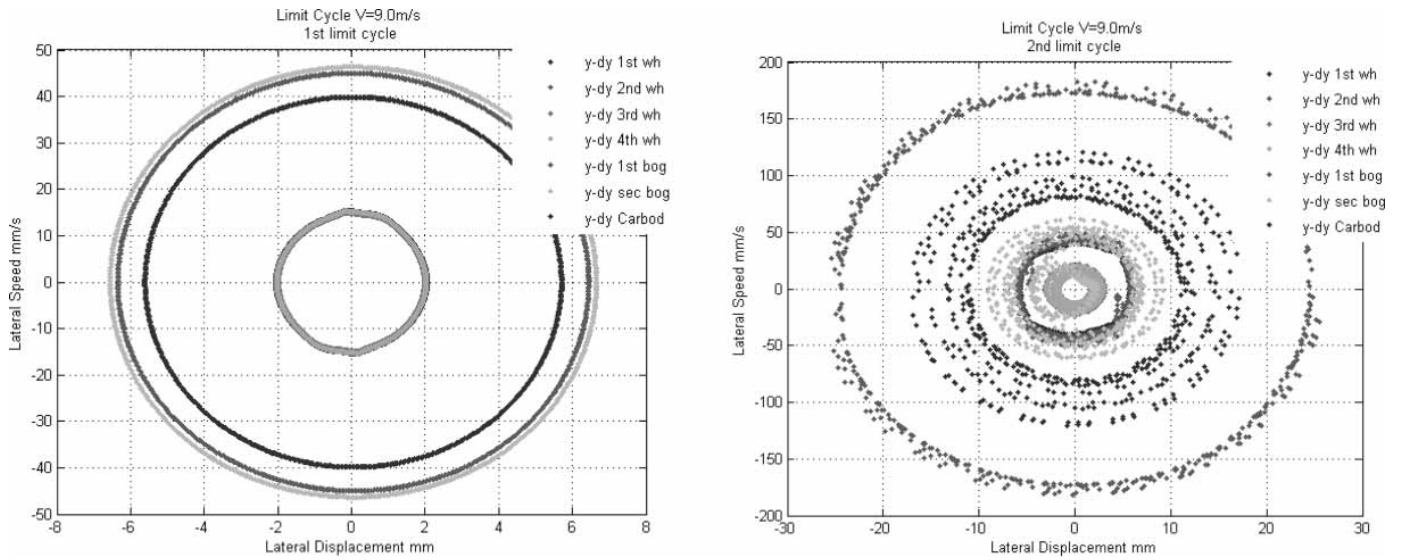

Fig. 17 Two limit cycles for $9.0 \mathrm{~m} / \mathrm{s}$ (BA661)

$4 \mathrm{~m} / \mathrm{s}$. In this speed lateral amplitudes for wheelsets are $0.9 \mathrm{~mm}$ and for bogies are about $1.5 \mathrm{~mm}$. The amplitude of oscillations increases by increasing the speed to $11.0 \mathrm{~m} / \mathrm{s}$. In this speed bogie frames have lateral amplitude of $25.0 \mathrm{~mm}$ that is very critical. After $26 \mathrm{~m} / \mathrm{s}$ lateral amplitudes of bogie frames decrease and lateral amplitudes of wheelsets increase. As have been showed for $30 \mathrm{~m} / \mathrm{s}$ there are flange contacts between wheels and rails and also lateral amplitude of bogie frames are less than $2 \mathrm{~mm}$.

Figure 16 shows the search for non-linear critical speed. Simulation has been started from speed $28 \mathrm{~m} / \mathrm{s}$ and after $10 \mathrm{~s}$ the speed has been reduced to reach $1.5 \mathrm{~m} / \mathrm{s}$. In this figure lateral oscillations of fourth wheelset and its bogie frame are between 28 and $1.5 \mathrm{~m} / \mathrm{s}$. As the figure shows there is oscillation in all speeds. Results for different decelerations are the same. Regarding to Figs 15 and 16 the wagon has secondary hunting mode in speeds about $30 \mathrm{~m} / \mathrm{s}$ and also primary hunting mode in speeds about $11.0 \mathrm{~m} / \mathrm{s}$.

Figure 17 shows two limit cycles for $9.0 \mathrm{~m} / \mathrm{s}$. The second limit cycle has been calculated by means of decreasing the speed from $12.0 \mathrm{~m} / \mathrm{s}$ and staying on $9.0 \mathrm{~m} / \mathrm{s}$ for $100 \mathrm{~s}$.

\section{CONCLUSIONS}

In the current research critical speed of the BA652freight truck has been found that is $50.0 \mathrm{~km} / \mathrm{h}$. Results show that in dynamical responses of this freight truck there are chaotic limit-cycles and saddle nodes. Also it has been showed that for speeds between 15.2 and $15.6 \mathrm{~m} / \mathrm{s}$ depend on initial conditions, there are two limit-cycles. Amplitude of oscillations of different parts in limit cycles depends on the vehicle speed. Primary hunting has been happened about $15 \mathrm{~m} / \mathrm{s}$ and secondary hunting after $51.0 \mathrm{~m} / \mathrm{s}$.

For old BA661-freight truck the conditions are critical and carbody can oscillate in very low speeds and with high amplitudes. Both primary and secondary hunting modes can be seen in results and oscillations about $11.0 \mathrm{~m} / \mathrm{s}$ and after $28.0 \mathrm{~m} / \mathrm{s}$ are chaotic.

In dynamical models for these two freight bogies, only the characteristics of primary suspension have been different that can be seen in Table 2. Both primary suspension systems have been tested with the same test structure. Comparing results of simulations for these two sets of parameters shows that primary suspension must be checked carefully in the 
maintenance centre. Frictions between leaves, bolt and parabolic spring, bolt and chain stone, chain link and chain stone and also the stiffness of leaf spring must be enough to avoid instability in freight wagons.

The same analyses for Y25 freight bogie [10] show that the critical speed is $61.2 \mathrm{~km} / \mathrm{h}$. Also in the primary hunting mode the lateral displacement of carbody for Y25 freight truck is less than $10 \mathrm{~mm}$ but for BA652 it is more than $15 \mathrm{~mm}$. In the primary suspension, longitudinal clearance for Y25 is $4 \mathrm{~mm}$ in one side and for BA652 it is $\pm 6 \mathrm{~mm}$ (12 mm) and also lateral clearance for Y25 is $\pm 10 \mathrm{~mm}$ and for BA652 it is $\pm 23 \mathrm{~mm}$. On the other hand, tests of primary suspension for these two types of freight bogies show that stiffness in lateral and longitudinal directions of BA652 are less than Y25 (about half of Y25 suspension). Because of these low stiffness and high clearances, BA type bogies are known as steering freight bogies. Results show that increasing the steerability of bogie decreases the hunting speed. In addition to primary suspension, side bearers of Y25 have preloaded springs with frictional pads that help to stability of motions.

\section{ACKNOWLEDGEMENTS}

The authors would like to thank Professor Hans True (DTU of Denmark) for his very useful documents and Dr Moelle (AgreCare Co.) for RSGEO Software.

\section{REFERENCES}

1 True, H. On the theory of nonlinear dynamics and its applications in vehicle systems dynamics. Veh. Syst. Dyn., 1999, 31, 393-421.
2 Pascal, J. P. Oscillations and chaotic behavior of unstable railway wagons over long distances. Chaos Solutions Fractals, 1995, 5(9), 1725-1753.

3 True, H. Does a critical speed for railroad vehicle exist? In Proceeding of the IEEE/ASME Joint Railroad Conference, 1994, pp. 125-131.

4 Jensen, $\mathbf{C}$. $\mathbf{N}$. and True, $\mathbf{H}$. On a new route to chaos in railway dynamics. Nonlin. Dyn., 1997, 13, 117-129.

5 Jensen, C. N., Golubitsky, M., and True, H. Symmetry, generic bifurcations, and ode interaction in nonlinear railway dynamics. Int. J. Bifur. Chaos, 1999, 9(7), 1321-1331.

6 Xia, F. and True, H. The dynamics of the three-piecefreight truck. Veh. Syst. Dyn., 2004, 41, 212-22l.

7 True, H. and Asmund, R. The dynamics of railway freight wagon wheelset with dry friction damping. Veh. Syst. Dyn., 2002, 38(2), 149-163.

8 Guidelines to best practices for heavy haul railway operations: wheel and rail interface issues, 2001 (International Heavy Haul Association, Virginia).

9 Hecht, M. European freight vehicle running gear today's position and future demands. Proc. Instn Mech. Engrs, Part F: J. Rail and Rapid Transit, 2001, 215, 1-11.

10 Molatefi, H., Hecht, M., and Kadivar, M. H. Critical speed and limit cycles in the empty Y25-freight truck. Proc. IMechE, Part F: J. Rail and Rapid Transit, 2006, 220, 347-359.

11 Schirmer, A. Beitrag zur Prinzipfindung und fahrzeugdynamischen Auslegung eines neuen GuterwagenDrehgestells, 2005 (Shaker Verlag, Aachen).

12 Kolsch, H. Schwingungsdämpfung durch statische Hysterese. VDI-Fortschritts-bericht, Reihe 11, Nr. 190, Düsseldorf, 1993.

13 White, R. C., Limbery, D. A., Hedrick, J. K., and Cooperider, N. K. Guideway suspension trade-offs in rail vehicle systems. Report DOT-OS-50107, US Department of Transportation, Washington DC, 1978.

14 Dukkipati, R. V. and Amyot, J. R. Computer-aided simulation in railway dynamics, 1988 (Marcel Dekker, New York, USA). 
